\title{
Role of Cord Blood Albumin and Bilirubin for Prediction of Significant Neonatal Jaundice
}

\author{
Nidhi Gupta ${ }^{1}$, Shachi Jain Taran ${ }^{2}$, Surabhi Gupta ${ }^{3}$ and Kewal Kishore Arora ${ }^{1}$ \\ ${ }^{1}$ Department of Paediatrics, Sri Aurobindo Medical College and Postgraduate Institute, Indore, India \\ ${ }^{2}$ Department of Paediatrics, Mahatma Gandhi Memorial Medical College, Indore, India \\ ${ }^{3}$ Consultant Gynaecology, Indore, India
}

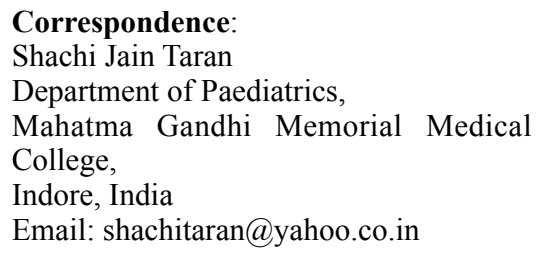

Department of Paediatrics,

Mahatma Gandhi Memorial Medical College,

Indore, India

Email: shachitaran@yahoo.co.in

\section{DOI: $10.3126 /$ jnps.v41i2.30383}

Submitted on: $2020-08-18$

Accepted on: 2021-02-14

\section{Acknowledgements: None}

Funding: Nil

Conflict of Interest: None declared

Permission from IRB: Yes

To cite this article: Gupta N, Taran SJ, Gupta S, Arora KK. Role of Cord Blood Albumin and Bilirubin for Prediction of Significant Neonatal Jaundice. J Nepal Paediatr Soc. 2021;41(2):239-46.

\begin{abstract}
Introduction: Nearly $60-80 \%$ of the term and preterm neonates are affected due to rise in bilirubin levels during early postnatal days, and causes readmission of the neonate sometimes with severe jaundice, which can be reduced if neonatal hyperbilirubinemia can be predicted early. The study was conducted to evaluate the predictive values of cord blood albumin and bilirubin for neonatal hyperbilirubinemia and to evaluate the better predictor between them.
\end{abstract}

Method: In this hospital based observational study, 152 healthy term newborns with birth weight more than $2.5 \mathrm{~kg}$ were included. Assessment of cord blood haemoglobin, blood group, albumin and bilirubin levels was done. Follow-up for first consecutive five days after birth was done and assessed daily to look for evidence of jaundice, sepsis or any other illness. Serum bilirubin was evaluated at 72-96 hours of life in all neonates and was done early, if clinically indicated. Receiver's Operating Characteristics curves were used for calculating the cut-off values of cord blood albumin and bilirubin in relation to hyperbilirubinemia.

Result: The cut-off values obtained for albumin and bilirubin of cord blood was $<2.56 \mathrm{mg} / \mathrm{dL}$ and $>2.33 \mathrm{mg} / \mathrm{dL}$ respectively at optimum sensitivity and specificity. Cord blood bilirubin was found to be highly sensitive for early recognition of significant neonatal hyperbilirubinemia as compared to cord blood albumin and can be used for screening purpose.

Conclusion: Cord blood albumin and bilirubin can be used for negating the development of NNHB, but for screening purpose, cord blood bilirubin is more predictive of neonatal hyperbilirubinemia.

Keywords: cord blood albumin; cord blood bilirubin; neonatal hyperbilirubinemia

(CC) This work is licensed under creative common attribution 3.0 license




\section{INTRODUCTION}

Jaundice is one of the most common problems encountered in the newborns. ${ }^{1}$ Most of the times, it is physiological as the liver maturity has not been complete. There is inability of neonatal liver to take care of high bilirubin levels which is a result of higher circulating volume of erythrocyte and with a smaller erythrocyte life-span, usually called "bilirubin peak." During this time, there is also ongoing transition of metabolism of bilirubin from foetal to adult stage. ${ }^{2}$ This is generally a benign condition, but sometimes this bilirubin peak can go up to harmful level. At times, untreated high level of serum bilirubin in newborn can lead to bilirubin encephalopathy, which can result in kernicterus and have long term consequences. Hence, early detection of hyperbilirubinemia and needful treatment is the need of the hour.

The synthesis of albumin is done in the liver and it helps in transportation of unconjugated bilirubin. Cord blood bilirubin and albumin level may be able to predict significant hyperbilirubinemia in the babies. Studies have shown good diagnostic accuracy of cord blood albumin and bilirubin in prediction of neonatal hyperbilirubinemia. ${ }^{3}$ In recent times, few studies have been conducted on prediction of neonatal hyperbilirubinemia using cord blood albumin and bilirubin. Both being noninvasive procedure and minimal cost, parents will give their consent easily for conducting these tests. These studies have recommended undertaking further research to find out the ethnic and geographical impact and to formulate guidelines as per requirement.

Hence, we undertook this study to evaluate the diagnostic accuracy of cord blood albumin and bilirubin to evaluate the predictive value for neonatal hyperbilirubinemia and formulate customised guidelines for "early prediction of neonatal hyperbilirubinemia" in our institution.

\section{METHODS}

The present study is a hospital based prospective observational study carried out in the Department of Paediatrics of a tertiary care teaching institute in central India from January 2017 to June 2018. One hundred and fifty two full term healthy neonates delivered during this period, fulfilling the inclusion criteria were included. A voluntary consent was obtained from the parents of the neonate for allowing participation.

The healthy term baby (Gestational age $>37$ weeks) (based on last menstrual period or by first trimester USG) with birth weight $>2.5 \mathrm{~kg}$ (weighed on electronic weighing scale, accurate up to 10 grams) were included in the study. Newborns with development of jaundice in the first 24 hours of life, $\mathrm{ABO}$ and $\mathrm{Rh}$ incompatibility, preterm, direct hyperbilirubinemia, cord blood bilirubin $>4 \mathrm{mg} / \mathrm{dL}$ and co-morbidities requiring NICU admission (sepsis, asphyxia, respiratory distress etc) were excluded from the study.

A detailed maternal and newborn history was obtained. All babies were carefully examined on first day of life. Complete physical examination including weight, temperature, gestational age, heart rate, capillary refilling time, colour of skin, edema, cyanosis, birth trauma, any sign suggestive of sepsis, was carried out till next five postnatal days.

Daily physical assessment of hyperbilirubinemia was done in accordance with Kramer's Dermal Zone. Peripheral venous blood was collected and serum bilirubin was assessed at $72-96$ hours of age or earlier if required, which was based on physical examination. Significant hyperbilirubinemia was defined as: Serum bilirubin $>12 \mathrm{mg} / \mathrm{dL}$ between $24-48$ hours of age, serum bilirubin $>15 \mathrm{mg} / \mathrm{dL}$ between $48-72$ hours of age or serum bilirubin $>17 \mathrm{mg} / \mathrm{dL}$ after 72 hours of age.

Neonates with significant hyperbilirubinemia were treated with phototherapy or exchange transfusion, as indicated. Serum bilirubin and serum albumin estimation was done using VITROS $\mathrm{BuBc}$ and VITROS ALB slide method. The sample size basis was a previous study which had reported prevalence of significant hyperbilirubinemia to be $10 \%$. Based on this fact, sample size obtained was 144 at a confidence interval of $95 \%$ and $80 \%$ power of the study. Accordingly 152 neonates were enrolled. 


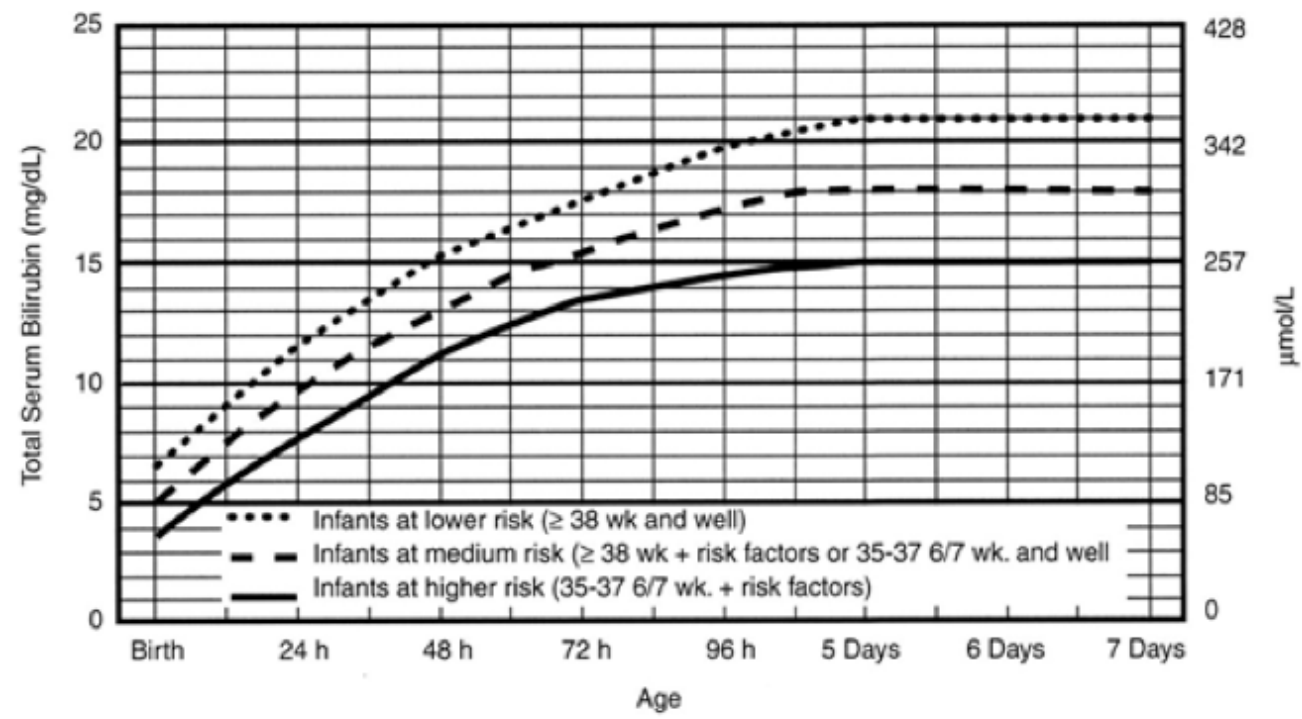

- Use total bilirubin. Do not subtract direct reacting or conjugated bilinubin.

- Risk factors = isoimmune hemolytic disease, G6PD deficiency, asphyxia, significant lethargy, temperature instability,

sepsis, acidosis, or albumin $<3.0 \mathrm{~g} / \mathrm{dL}$ (if measured)

- For well intants 35-37 6/7 wk can adjust TSB levels for intervention around the medium risk line. It is an option to

intervene at lower TSB levels for infants closer to 35 wks and at higher TSB levels for those closer to $376 / 7$ wk.

- It is an option to provide conventional phototherapy in hospital or at home at TSB levels $2.3 \mathrm{mg} / \mathrm{dL}$ (35.50mmoll $)$

below those shown but home phototherapy should not be used in any infant with risk factors.

Figure 1. Guidelines for phototherapy in hospitalised infant of 35 or more weeks of gestation

$P$ values were calculated using statistical software like GraphPad, MedCalc. Receiver operating characteristics was used for calculating cut-off values. Association between two non-parametric variables was seen using Pearson Chi-square test. Comparison between means of two groups was done using Unpaired ' $t$ ' test. Correlation between two parametric variables was done using Pearson correlation coefficient. A $p$ value of $<0.05$ was taken as statistically significant.

All ethical considerations were kept while conducting the research. Approval from institutional ethics committee was taken for the study.

\section{RESULTS}

The mean age of 152 neonates was 2.88 days with a range of 2.50 to 3.81 days. Of these 152, 103 $(67.7 \%)$ neonates were exclusively breastfed and $49(32.2 \%)$ neonates were on mixed feeds. Eighty six (56.6\%) were males and 66 (43.4\%) females, showing a male preponderance. The mean birth weight was comparable between neonates with and without significant hyperbilirubinemia $(2.88 \pm 0.19$ $\mathrm{kg}$ vs. $2.88 \pm 0.32 \mathrm{~kg}$ respectively), $\mathrm{p}=0.995$.
There were $55.3 \%$ primigravidae and $44.7 \%$ multigravidae mothers. Sixty one (40.1\%) neonates were born through Caesarean section and 91 $(59.9 \%)$ neonates were delivered vaginally. Significant neonatal hyperbilirubinemia was seen in $17(11.2 \%)$ neonates and in rest it was absent. (Table 1) .

$12.8 \%$ males and $9.1 \%$ females were having significant neonatal hyperbilirubinemia. Of the 103 neonates who were exclusively breastfed, $15.5 \%$ neonates had significant neonatal hyperbilirubinemia and $2.0 \%$ of the neonates who were on mixed feeding had high bilirubin level. The mean cord blood bilirubin in exclusively breastfed newborns was $2.05 \pm 0.57 \mathrm{mg} / \mathrm{dL}$ and in mixed fed newborns was $1.94 \pm 0.53 \mathrm{mg} / \mathrm{dL}$. The mean cord blood bilirubin among the exclusive breastfed and mixed fed was not significant $(\mathrm{p}=$ 0.239). But the mean cord blood albumin was significantly higher in the mixed fed in comparison to the exclusively breastfed infants $(\mathrm{p}=0.001)$. (Table 2)

The mean cord blood bilirubin was significantly higher in significant neonatal jaundice group in comparison to the non-significant neonatal jaundice 
Table 1. Distribution of NNHB (Neonatal Hyperbilirubinemia) in newborns

\begin{tabular}{|llrr|}
\hline SN & $\begin{array}{l}\text { Neonatal } \\
\text { hyperbilirubinemia } \\
\text { (NNHB) }\end{array}$ & Frequency & Percent \\
\hline 1 & $\begin{array}{l}\text { Neonatal } \\
\text { Hyperbilirubinemia present }\end{array}$ & 17 & 11.2 \\
\hline 2 & $\begin{array}{l}\text { Neonatal } \\
\text { Hyperbilirubinemia absent }\end{array}$ & 135 & 88.8 \\
& Total & 152 & 100.0
\end{tabular}

group $(\mathrm{p}=0.001)$. The mean cord blood albumin was significantly lower in significant neonatal jaundice group in comparison to the non-significant neonatal jaundice group $(\mathrm{p}=0.001)($ Table-3).

The resulting AUC was 0.768, suggesting a "fair" diagnostic test for predicting severe neonatal hyperbilirubinemia. The cut-off value obtained was $\leq 2.56 \mathrm{gm} / \mathrm{dL}$. A cord blood albumin value of less than or equal to $2.56 \mathrm{gm} / \mathrm{dL}$ was predictive of neonatal hyperbilirubinemia. At this cut-off the sensitivity of the test was found to be $70.59 \%$, specificity was $83.70 \%$, positive predictive value was $35.29 \%$, negative predictive value was $95.76 \%$ and diagnostic accuracy was $82.24 \%$. The specificity, negative predictive value and diagnostic accuracy of cord blood serum albumin is very high, but sensitivity and positive predictive value is poor. Hence, this test cannot be used for screening for neonatal hyperbilirubinemia, but can be definitely used for negating (absence) neonatal hyperbilirubinemia development later on.
Table 2. Comparison of mean cord blood bilirubin and albumin between the exclusively breastfed and mixed fed newborns

\begin{tabular}{|c|c|c|c|c|c|}
\hline Parameter & Group & No & $\begin{array}{l}\text { Mean } \\
\pm \text { SD }\end{array}$ & $\begin{array}{c}\text { 't' } \\
\text { value }\end{array}$ & $\begin{array}{c}P \\
\text { value }\end{array}$ \\
\hline \multirow[t]{2}{*}{$\begin{array}{l}\text { Cord blood } \\
\text { bilirubin }\end{array}$} & $\begin{array}{l}\text { Exclusively } \\
\text { breastfed }\end{array}$ & 103 & $\begin{array}{r}2.05 \pm \\
0.57\end{array}$ & \multirow{2}{*}{$\begin{array}{r}1.183 \\
\mathrm{df}= \\
150\end{array}$} & \multirow[t]{2}{*}{$\begin{array}{r}0.239, \\
\text { NS }\end{array}$} \\
\hline & Mixed fed & 49 & $\begin{array}{r}1.94 \pm \\
0.53\end{array}$ & & \\
\hline \multirow[t]{2}{*}{$\begin{array}{l}\text { Cord blood } \\
\text { albumin }\end{array}$} & $\begin{array}{l}\text { Exclusively } \\
\text { breastfed }\end{array}$ & 103 & $\begin{array}{r}2.83 \pm \\
0.51\end{array}$ & \multirow{2}{*}{$\begin{array}{r}-4.856 \\
\mathrm{df}= \\
150\end{array}$} & \multirow[t]{2}{*}{$\begin{array}{r}0.001 \\
*\end{array}$} \\
\hline & Mixed fed & 49 & $\begin{array}{r}3.24 \pm \\
0.42\end{array}$ & & \\
\hline
\end{tabular}

Unpaired ' $t$ ' test applied. $P$ value $<0.05$ was taken as statistically significant.

The resulting AUC was 0.948, suggesting an "excellent" diagnostic test to predict severe neonatal jaundice. The cut-off value obtained was $>$ $2.33 \mathrm{mg} / \mathrm{dL}$. A cord blood bilirubin value of greater than $2.33 \mathrm{mg} / \mathrm{dL}$ was predictive of neonatal hyperbilirubinemia. At this cut-off the sensitivity of the test was found to be $94.12 \%$, specificity was $86.67 \%$, positive predictive value was $47.06 \%$, negative predictive value was $99.15 \%$ and diagnostic accuracy was $87.50 \%$. The sensitivity, specificity, negative predictive value and diagnostic accuracy of cord blood serum bilirubin is very high, but positive predictive value is poor. Hence, this test can be used for predicting Neonatal hyperbilirubinemia but caution should be taken as it has a poor positive predictive value tending to give higher false positive. On the basis of very high negative predictive value, but can be definitely used for negating (absence) the development of neonatal hyperbilirubinemia.

Table 3. Comparison of mean cord blood bilirubin and albumin between the significant neonatal jaundice and nonsignificant neonatal jaundice groups

\begin{tabular}{|c|c|c|c|c|c|}
\hline Parameter & Group & No. & Mean \pm SD & t'value & P value \\
\hline \multirow[t]{2}{*}{ Cord blood bilirubin } & Significant neonatal jaundice & 17 & $2.90 \pm 0.44$ & $8.455, \mathrm{df}=150$ & $0.001 *$ \\
\hline & $\begin{array}{l}\text { Non-significant neonatal } \\
\text { jaundice }\end{array}$ & 135 & $1.90 \pm 0.46$ & & \\
\hline \multirow[t]{2}{*}{ Cord blood albumin } & Significant neonatal jaundice & 17 & $2.53 \pm 0.67$ & $-3.823, \mathrm{df}=150$ & $0.001^{*}$ \\
\hline & $\begin{array}{l}\text { Non-significant neonatal } \\
\text { jaundice }\end{array}$ & 135 & $3.02 \pm 0.47$ & & \\
\hline
\end{tabular}

Unpaired ' $t$ ' test applied. P value $<0.05$ was taken as statistically significant. 


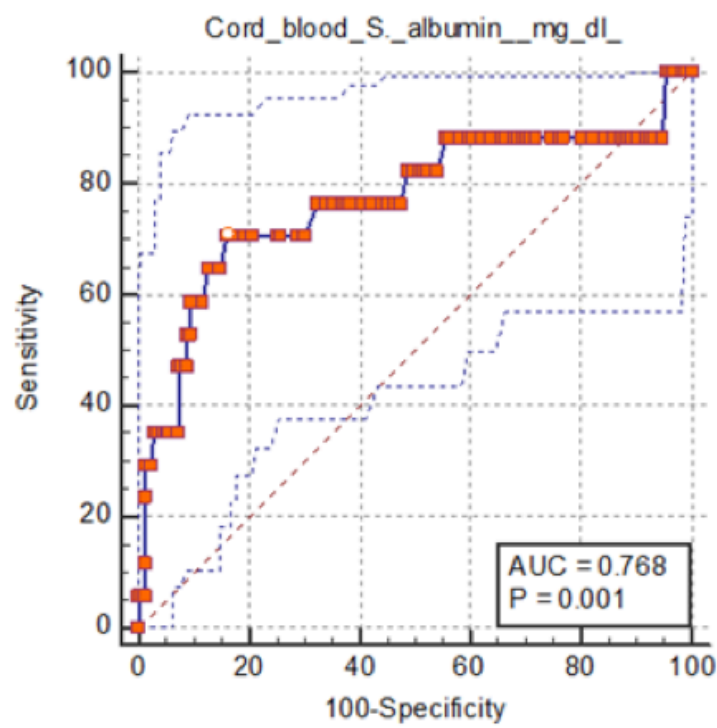

Figure 2. ROC between cord blood albumin and clinical NNHB

The correlation coefficient ' $r$ ' obtained was -0.213 with a $\mathrm{p}$ value of 0.004 between albumin in cord blood and serum bilirubin at 72 - 96 hours, which showed that there is an inverse relationship between albumin level in cord blood and serum bilirubin at $72-96$ hours. This correlation is very weak, but statistically significant. (Table 4)

The correlation coefficient ' $\mathrm{r}$ ' obtained was 0.504 with a $p$ value of 0.001 between bilirubin level in cord blood and serum bilirubin at 72 - 96 hours, which showed that there is a positive relationship between bilirubin level in cord blood and serum bilirubin at 72 - 96 hours. This correlation is good and statistically significant. (Table 4)

Table 4. Correlation between cord blood albumin and bilirubin with serum bilirubin at $72-96$ hours

\begin{tabular}{|c|c|c|c|}
\hline Pair & $\begin{array}{c}\text { 'r' } \\
\text { value }\end{array}$ & P value & Significance \\
\hline $\begin{array}{l}\text { Cord blood } \\
\text { albumin to Serum } \\
\text { bilirubin level at } 72 \\
\text { - } 96 \text { hours }\end{array}$ & -0.213 & $0.004 *$ & $\begin{array}{l}\text { Very weak, } \\
\text { negative } \\
\text { statistically } \\
\text { significant } \\
\text { correlation }\end{array}$ \\
\hline $\begin{array}{l}\text { Cord blood } \\
\text { bilirubin to Serum } \\
\text { bilirubin level at } 72 \\
-96 \text { hours }\end{array}$ & 0.504 & 0.001 & $\begin{array}{l}\text { Strong, } \\
\text { positive } \\
\text { statistically } \\
\text { significant } \\
\text { correlation }\end{array}$ \\
\hline
\end{tabular}

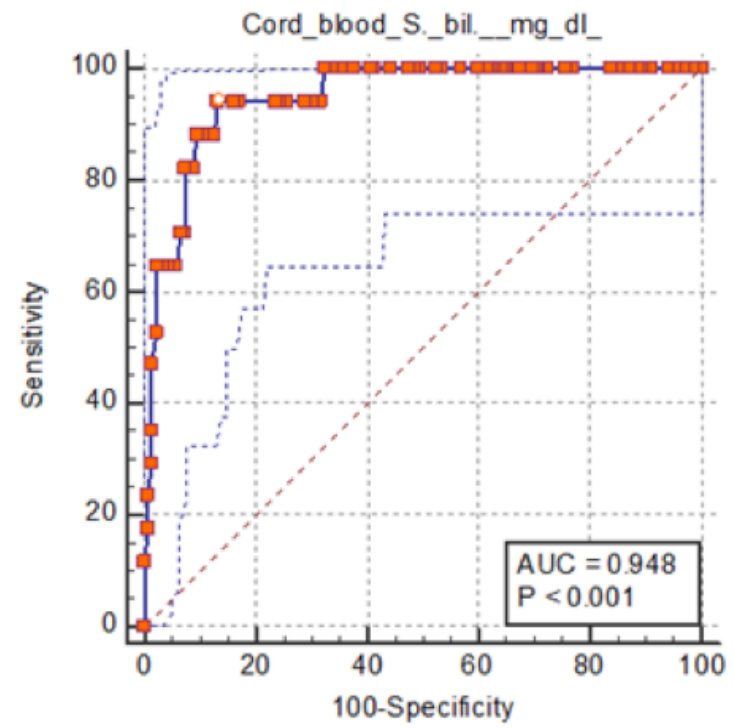

Figure 3. ROC between cord blood bilirubin and clinical NNHB

\section{DISCUSSION}

It has always been a subject of discussion about the length of stay of the newborn mother dyad in the institution, safety and danger of before time hospital discharge (jaundice, feeding problem, screening, anomaly detection) and designing a follow-up plan for each nation considering its economic constraint, community attitude, health infrastructure etc.

Neonatal hyperbilirubinemia has been found to be the most prevalent reason for readmission of the newborns. ${ }^{5}$ The most recent guideline of AAP 2004 states that infants discharged before 24 hours of age should be seen at 72 hours of age, discharged between $24-48$ hours of age at 96 hours of age, and those discharged between 48 and 72 hours of age should be seen at $5^{\text {th }}$ day of life. ${ }^{4}$ However in our country a complete follow up is not always possible because of non compliance and lack of medical facilities in peripheral areas. Thus there is utmost need for framing up our own discharge policy and follow up program, since neonatal hyperbilirubinemia can be treated easily. Identifying high risk newborn and ensuring their follow up or delaying discharge is very important.

In this study, we aimed to determine the future risk of neonatal hyperbilirubinemia by predictive ability of cord blood bilirubin and cord blood albumin 
level in term newborn without any risk factor for subsequent significant neonatal hyperbilirubinemia development. In our study, out of 152 newborns 17 (11.2\%) newborns developed significant neonatal hyperbilirubinemia requiring phototherapy. Studies done by other authors reported a variation from 8.3 to $12.8 \%$ in the incidence of significant neonatal hyperbilirubinemia depending upon region, ethnic constitution of the population, laboratory standard variability in the bilirubin measurement. ${ }^{6}$

Exclusive breast feeding was found to be significantly associated with the increased risk of NNHB in our study. Maisels et al. (2009) in their study suggests exclusive breast feeding and gestational age being the two most important clinical factors for significant neonatal hyperbilirubinemia development. ${ }^{7}$ In our study, a positive statistically significant correlation between cord blood bilirubin and serum bilirubin level was observed $(p$ value $=0.001)$.

The relationship between the clinical sensitivity and specificity with respect to every possible cutoff value of cord blood bilirubin was constructed using ROC curve. The point with maximum sensitivity (94.12\%) and specificity (86.67\%) was found at value of more than $2.33 \mathrm{mg} / \mathrm{dl}$, with area under curve 0.948. Positive predictive value and negative predictive value at this point were found to be $47.06 \%$ and $99.15 \%$ respectively. In another prospective study conducted by Bernaldo et al. in 2004, in which they had included 380 full term newborns, few had blood group incompatibility while others were without any complications. They concluded $53 \%$ of their newborns with higher levels of cord blood unconjugated bilirubin ( $>2.0$ $\mathrm{mg} / \mathrm{dl}$ ) required phototherapy at third day after birth. ${ }^{8}$ Higher percentage of significant jaundice in this study as compared to ours may be because they have taken high risk cases also. In another study, 84 stable newborns were followed-up for initial five days. Study of ROC found that the bilirubin level in cord blood $>2.5 \mathrm{mg} / \mathrm{dL}$ had a sensitivity of $77 \%$ (high) and precision of $98.6 \%$ (high) to predict occurrence of severe jaundice. ${ }^{9}$ Likewise a study by Khare et al. provides an overview of the ROC curve. A cut-off value for cord blood bilirubin level $>1.875 \mathrm{mg} / \mathrm{dl}$ indicates sensitivity, precision, positive predictive value, and the negative predictive value of $76.8 \%, 61.3 \%, 81.5 \%$, and $54.3 \%{ }^{10}$

We constructed ROC in our study also for albumin of the cord blood. Albumin level of less than or equal to $2.56 \mathrm{gm} / \mathrm{dl}$ seems best as predictive value with sensitivity $70.59 \%$ and specificity $83.7 \%$. Positive and negative predictive value at this point was found to be $35.29 \%$ and $95.76 \%$ respectively.

In a study carried out by Rashed et al. on 150 term and preterm newborns, there was significant relationship between albumin of cord blood and neonatal hyperbilirubinemia $(p=0.001)$ in both categories. ${ }^{10}$ In term group $61.2 \%$ newborns with cord serum albumin $<2.8 \mathrm{gm} / \mathrm{dL}$ developed neonatal hyperbilirubinemia. $32.3 \%$ newborns had albumin level in cord blood between $2.9-3.3 \mathrm{gm} /$ $\mathrm{dl}$, and only $6.5 \%$ of the newborns with cord serum albumin level $\geq 3.4 \mathrm{gm} / \mathrm{dL}$ developed significant hyperbilirubinemia. ${ }^{11}$

A hospital based study conducted by Aiyappa et al. on 165 healthy term neonates showed cord serum albumin $\leq 2.8 \mathrm{gm} / \mathrm{dL}$ had sensitivity $71.8 \%$, specificity $65.1 \%$, positive predictive value $38.9 \%$ and negative predictive value $88.2 \%$, with $\mathrm{ROC}$ curve showing area under curve $(\mathrm{AUC})=0.684$. Our study results are parallel to this study too with AUC $0.735 . .^{12}$ In the research conducted by Rajpurohit et al., the albumin level cut-off of 2.6 $\mathrm{gm} / \mathrm{dL}$ in cord blood with a high sensitivity ( 80 per cent), specificity ( 86.67 per cent) was selected. The positive and negative predictive value were 40 per cent and 97.5 per cent respectively, at this point. ${ }^{13}$ This study also favours more negative predictive value of test.

Haridas et al. in their study on 500 healthy neonate found that umbilical cord blood bilirubin level $>$ $1.78 \mathrm{gm} / \mathrm{dL}$ was $90 \%$ sensitive and $87 \%$ specific with a PPV of $75 \%$ and NPV of $92 \%$ in predicting significant neonatal hyperbilirubinemia. ${ }^{14}$ The results are different from our study as in our study positive predictive value is quite low and bilirubin level 2.33 is significant. Similarly Bhat et al. on their study on 300 newborns found that $11 \%$ of them developed significant jaundice and cord blood 
bilirubin $>3 \mathrm{mg} / \mathrm{dL}$ and albumin less than $2.4 \mathrm{gm} /$ $\mathrm{dL}$ are predictors of significant jaundice requiring treatment. ${ }^{15}$ In our study, the predictive value of cord blood bilirubin was found to be greater than the predictive value of albumin in cord blood, with higher sensitivity and specificity being obtained on the ROC curve analysis at the cut-off point and larger area under curve.

Our study population consisted of healthy term babies not in high risk group. This is most important point of our study. And we also found these two tests to be more important for ruling out risk of jaundice. We believe that data from this study could be applied to low risk and especially will help to screen babies who develop NNHB despite ruling out other risk factors. Though different studies are stating slightly different level of cord blood bilirubin and albumin for predicting severe jaundice, may be due to difference in study population structure, but all found significant results. Small sample size was the only limitation of our study.

\section{CONCLUSIONS}

In this study we found that bilirubin level more than $2.33 \mathrm{mg} / \mathrm{dL}$ and albumin level less than or equal to $2.56 \mathrm{gm} / \mathrm{dL}$ of the cord blood can be used as a predictive index for development of significant
NNHB, with cord blood bilirubin being more sensitive and specific marker than cord blood albumin. Both the tests have greater negative predictive value. Classifying newborns at low risk for hyperbilirubinemia minimise unnecessary prolongation of hospitalisation as it will provide more confidence to neonatologists in decision of early discharge. Babies with high-risk category can be asked for early follow-up or parents can be counselled for need of delayed discharge if timely follow up cannot be ensured. So that simple, safe and economic phototherapy as a treatment option can be provided to reduce neonatal morbidity and mortality.

Based on the results obtained, the authors of the study recommend for large sized studies to be carried out so that an in-depth information regarding the relationship between raised cord blood bilirubin and lower cord blood albumin; with neonatal jaundice could be established.

\section{REFERENCES}

1. Porter ML, Dennis BL. Hyperbilirubinemia in the term newborn. Am Fam Physician. 2002 Feb 15;65(4):599-606. PMID: 11871676.

2. Ullah S, Rahman K, Hedayati M. Hyperbilirubinemia in Neonates: Types, Causes, Clinical Examinations, Preventive Measures and Treatments: A Narrative Review Article. Iran J Public Health. 2016 May;45(5):558-68. PMID: 27398328; PMCID: PMC4935699.

3. El Mashad GM, El Sayed HM, El Shafie WA. Cord blood albumin-bilirubin as a predictor for neonatal hyperbilirubinemia. Menoufia Med J. 2019;32:1071-7. DOI: 10.4103/mmj.mmj_13_18

4. American Academy of Pediatrics Subcommittee on Hyperbilirubinemia. Management of hyperbilirubinemia in the newborn infant 35 or more weeks of gestation. Pediatrics. 2004 Jul;114(1):297-316. DOI: 10.1542/peds.114.1.297. Erratum in: Pediatrics. 2004 Oct;114(4):1138. PMID: 15231951.

5. Maisels MJ, Kring E. Length of stay, jaundice, and hospital readmission. Paediatrics. 1998 Jun;101(6):995-8. DOI: 10.1542/peds.101.6.995. PMID: 9606225.

6. Raj RR, Sarangi GD. Cord serum albumin as a tool to predict neonatal hyperbilirubinemia. Index Copernicus International. 2016 Jul-Sep;5(3):131-36.

7. Maisels MJ, Bhutani VK, Bogen D, Newman TB, Stark AR, Watchko JF. Hyperbilirubinemia in the newborn infant $>$ or $=35$ weeks' gestation: an update with clarifications. Pediatrics. 2009 Oct;124(4):1193-8. DOI: 10.1542/peds. 2009-0329. PMID: 19786452. 
8. Bernaldo AJ, Segre CA. Bilirubin dosage in cord blood: could it predict neonatal hyperbilirubinemia? Sao Paulo Med J. 2004 May 6;122(3):99-103. DOI: 10.1590/s1516-31802004000300005.

9. Nahar Z, Shahidullah MD, Mannan A. The value of umbilical cord blood bilirubin measurement in predicting the development of significant hyperbilirubinemia in healthy newborn. Bangladesh J Child Health. 2009;33(2):50-4. DOI: https://doi.org/10.3329/bjch.v33i2.5677

10. Khare PM, Singh P. Correlation of cord blood bilirubin with significant neonatal hyperbilirubinemia in term newborns. IJAR. 2016 Jan;6(1):1-5. DOI : 10.36106/ijar

11. Reshad M, Ravichander B, Raghuraman TS. A study of cord blood albumin as a predictor of significant neonatal hyperbilirubinemia in term and preterm neonates. Int J Res Med Sci. 2016 Mar;4(3):887-90. DOI: http://dx.doi.org/ 10.18203/2320-6012.ijrms20160537

12. Aiyappa GKC, Shriyan A, Raj B. Cord blood albumin as a predictor of neonatal hyperbilirubinemia in healthy neonates. Int J Contemp Pediatr. 2017 Mar;4(2):503-6. DOI: http://dx.doi.org/10.18203/2349-3291.ijcp20170698

13. Rajpurohit N, Kumar S, Sharma D, Choudhary M, Purohit S. To Assess Predictive Value of Cord Blood Bilirubin and Albumin forSignificant Neonatal Hyperbilirubinemia: A Prospective Study from India. J Pediatr Neonatal Care. 2015;2(1):00060. DOI: 10.15406/jpnc.2015.02.00060.

14. Haridas K, Shinde R, Belavadi G. Prediction of neonatal hyperbilirubinemia usingumbilical cord blood bilirubin. Int J Contemp Pediatr. 2019 Mar;6(2):248-52. DOI: http://dx.doi.org/10.18203/2349-3291.ijcp20190676.

15. Bhat JA, Sheikh SA, Ara R. Cord blood bilirubin, albumin, and bilirubin /albumin ratio for predicting subsequent neonatal hyperbilirubinemia. Paediatr Indones. 2019 Jun 24;59(5):244-51. DOI: https://doi.org/10.14238/ pi59.5.2019.244-51. 